\title{
Analysis of Shear Stress and Rutting Performance of Semirigid Base Asphalt Pavement on Steep Longitudinal Slope
}

\author{
Jiafu Guo, ${ }^{1}$ Song Yang $\mathbb{D},{ }^{1}$ Yongchao Sun, ${ }^{1}$ Zhensheng Chao, ${ }^{1}$ Ruikang Yang $\mathbb{D},{ }^{2}$ \\ and Huailei Cheng ${ }^{2,3}$ \\ ${ }^{1}$ Powerchina Roadbridge Group Co., Ltd, Beijing, China \\ ${ }^{2}$ The Key Laboratory of Road and Traffic Engineering of Ministry of Education, Tongji University, Shanghai, China \\ ${ }^{3}$ Department of Civil and Environmental Engineering, The Hong Kong Polytechnic University, Hong Kong, China
}

Correspondence should be addressed to Ruikang Yang; rkyang@tongji.edu.cn and Huailei Cheng; chl6218@tongji.edu.cn

Received 11 August 2021; Accepted 9 October 2021; Published 21 October 2021

Academic Editor: Roberto Nascimbene

Copyright (c) 2021 Jiafu Guo et al. This is an open access article distributed under the Creative Commons Attribution License, which permits unrestricted use, distribution, and reproduction in any medium, provided the original work is properly cited.

Rutting is the most common distress of the asphalt pavement with a semirigid base, mainly when located on a steep longitudinal slope. Previous studies have shown that shear stress is the leading cause of rutting. Therefore, it is essential to analyze the distribution characteristics of shear stress to evaluate pavement rutting performance. Firstly, the truck speed was measured at different locations on the steep longitudinal slope section. Then, the calculation method of shear stress was improved based on the method of "systematic clustering." The distribution characteristics of shear stress were studied under the different gradients, slope lengths, horizontal forces, and interlayer bond conditions. Finally, the rutting prediction model was used to evaluate the rutting performance of the steep longitudinal slope section. The results show two critical parameters of a steep longitudinal slope: gradient and slope length can be quantified by establishing the relationship between truck speed and those parameters. The improved shear stress calculation method can correspond well with the layer where maximum rutting occurs. Gradients and slope lengths have little effect on shear stresses, while horizontal forces and interlayer bond conditions significantly change the shear stress distribution characteristics within the pavement. For the steep longitudinal slope sections, the rutting prediction model should consider the truck speed separately. With increasing gradient and slope length, the rutting increases the fastest in the middle layer. For sections with horizontal forces and poor interlayer bonding, the layers with the highest rutting accumulation are the upper layer and the lower layer, respectively.

\section{Introduction}

Rutting is the most common distress of the asphalt pavement with a semirigid base, mainly on a steep longitudinal slope $[1,2]$. This kind of distress can negatively impact driving comfort, safety, and pavement service life [3]. Therefore, it is essential to evaluate rutting performance before road construction and reconstruction.

The evaluation of rutting performance is mainly quantified by rutting depth, which is predicted by the rutting prediction model $[4,5]$. In most prediction models, the vertical compressive stress is a crucial input parameter. However, this parameter cannot explain the phenomenon that the maximum rutting occurs in the middle layer of the pavement. Sun et al. [3] explained this phenomenon from the aspect of shear stress distribution in pavement structures and proved the shear stress is more appropriate than vertical compressive stress in the rutting prediction model. Nie and Zhang [6] selected the maximum shear stress in the horizontal plane to study shear stress distribution in different pavement structures. Yoder and Witczak [7] thought that the surface at the outer edge of the load is a critical position for rutting, and this position was chosen to study the distribution of shear stress. Some researchers have also studied the relationship between shear stress and rutting [8-10]. However, the rutting is caused by the shear deformation of the overall asphalt layer [11]. The maximum shear stress at a certain depth or the whole pavement cannot represent the 
rutting distribution of the overall pavement well. Therefore, Wang and Sun $[3,12]$ suggested averaging the shear stress of different positions at a certain depth by considering the correspondence between the spatial distribution of rutting and shear stress distribution. However, the effect of horizontal forces and interlayer bond conditions are not considered in this method.

Analyzing factors affecting shear stress can help understand the rutting performance of the steep longitudinal slope better. The gradient is steeper for the steep longitudinal slope section, and the slope length is longer [1, 2]. These characteristics will make the truck speed much slower or higher than plain areas. Trucks with high speed will frequently brake and thus will apply large horizontal forces to the pavement surface. Moreover, the steep longitudinal slope section is more likely to have poor interlayer conditions. All these factors will affect the distribution of shear stress and the rutting performance of the pavement. Wang and AIQadi [13] compared the debonding and full bonding conditions. They found that debonding between the asphalt layer and semirigid base layer made the shear stress larger. Xiao et al. [14] found that the shear stress increased linearly with the increase of the truck speed. Temperature and horizontal force also impact shear stress to some extent [15-17].

The main objective of this study is to investigate the shear stress distribution and rutting performance of semirigid asphalt pavement on the steep longitudinal slope. Firstly, this paper used the "systematic clustering method" to improve the calculation method of shear stress. This method considered the horizontal forces and interlayer bonding conditions in pavements. Then, the speeds of trucks at different locations were measured to characterize the two essential parameters of the steep longitudinal slope, gradient, and slope length. A finite element model (FEM) was established to investigate the effects of gradient, slope length, horizontal force, and interlayer bond condition on shear stress. Finally, based on the calculated shear stresses and other related parameters, the rutting performance of the steep longitudinal slope section was evaluated.

\section{Establishment of Finite Element Model (FEM) and Determination of Input Parameters for Steep Longitudinal Slope Sections}

2.1. Geometry and Pavement Structure of the Model. The pavement structure is shown in Table 1, which is the most commonly used structure for the steep longitudinal slope section. The load used for FEM is shown in Figure 1. The contact area is measured by the actual loading vehicle. The size is $0.23 \mathrm{~m} \times 0.21 \mathrm{~m}$, and the interval between the two wheels is $0.34 \mathrm{~m}$. The pressure of the load is $0.688 \mathrm{MPa}$. The size of the finite element model is $10 \mathrm{~m} \times 10 \mathrm{~m} \times 15 \mathrm{~m}$, as shown in Figure 2, where $Z$ direction is the driving direction $(10 \mathrm{~m}), X$ direction is perpendicular to the driving direction $(10 \mathrm{~m})$, and $Y$ direction is the depth direction $(15 \mathrm{~m})$. The finite element model is static with the boundary conditions: the $X$ and $Z$ directions are constricted to the normal displacement, and the $Y$ direction is completely fixed. The grid is divided, as shown in Figure 2. Along the depth direction, the asphalt layer is divided by $1 \mathrm{~cm}$, the base and subbase layer are divided by $4 \mathrm{~cm}$, and the subgrade mesh is gradually sparse along the depth direction, with 20 meshes. To improve computational efficiency, the mesh division in the load area is dense and gradually becomes sparse away from the load area $[18,19]$.

2.2. Material Properties. The modulus of the base, subbase, and subgrade layer was obtained from the backcalculation of the field (FWD) evaluation [20]. The base and subbase layer modulus were $7871.1 \mathrm{MPa}$, and the modulus of the soil base was 118.2 MPa. Poisson's ratio was taken as 0.25 for the asphalt layer, base layer, subbase layer, and 0.4 for the subgrade layer according to the specification JTG D50 [5]. The modulus parameters of the asphalt layer are acquired by the uniaxial compression dynamic modulus test according to the specification JTG E20 [21]. Then, the dynamic modulus master curve can be established [22]. The modulus values of the asphalt layer can be calculated at the specific temperature and frequency. The dynamic modulus master curve is generally fitted by

$$
\log \left(\left|E^{*}\right|\right)=\delta+\frac{\alpha}{1+e^{\beta+\gamma\left(\log f+\log a_{T}\right)}} .
$$

where $\left|E^{*}\right|$ is the dynamic modulus, $\operatorname{MPa} ; \alpha, \beta, \delta, \gamma$ are the regression parameters; $f$ is the loading frequency, $\mathrm{Hz}$; and $a_{T}$ is the shift factor that converts the frequency at measured temperature to the frequency at the reference temperature. The formula for calculating $a_{T}$ is shown in

$$
\log \left(a_{T}\right)=\frac{C_{1}\left(T-T_{\mathrm{ref}}\right)}{C_{2}+T-T_{\mathrm{ref}}}
$$

where $C_{1}, C_{2}$ are fitting parameters, $T_{\text {ref }}$ is reference temperature, and $T$ is the actual temperature which needs to be calculated, ${ }^{\circ} \mathrm{C}$.

In this paper, the dynamic moduli of the above three different asphalt layers were measured. The dynamic modulus master curves were calculated and fitted according to JTG D50 [5]. The measured results and fitted parameters are shown in Figure 3.

Figure 3 and equations (1) and (2) show that the dynamic modulus master curve gives the relationship among different temperatures, loading frequencies, and the modulus. Through this relationship, the moduli of the asphalt layers can be calculated. For example, when the frequency is $10 \mathrm{~Hz}$, and the temperature is $40^{\circ} \mathrm{C}$, the moduli of AC-13, AC-20, and AC-25 layers are $1951.1 \mathrm{MPa}, 2537.1 \mathrm{MPa}$, and 2563.2 $\mathrm{MPa}$. So, it is first indispensable to determine the temperature and frequency before the modulus of asphalt layers before determining the moduli of asphalt layers.

\subsection{Determination of Effective Temperature for Asphalt} Layers. Yi et al. [23] established a prediction model on equivalent rutting temperature for asphalt layer at different depths considering regional differences and asphalt material 
TABle 1: Pavement structure.

\begin{tabular}{lcc}
\hline Layer & Thickness $(\mathrm{cm})$ & Structure \\
\hline & 4 & AC-13 SBS asphalt mixture \\
Asphalt layer & 6 & AC-20 SBS asphalt mixture \\
& 8 & AC-25 base asphalt mixture \\
Base layer & 20 & Cement stabilized macadam (CSM) \\
Subbase layer & 32 &
\end{tabular}

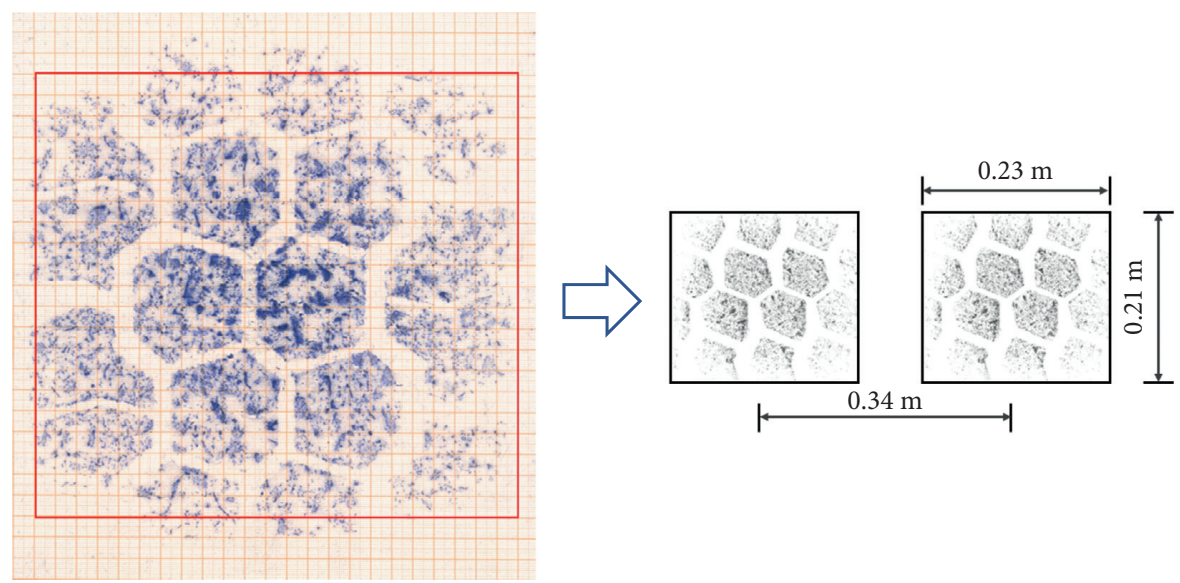

Figure 1: Load size and contact area.

properties, shown in equations (3) and (4). Aiming to study the rutting performance of steep longitudinal slope sections, this temperature model is chosen here for further study:

$$
\begin{aligned}
T_{e f f-V}= & -0.0091 d^{3}+0.2947 d^{2}-2.8622 d+0.5227 D D \\
& +0.0003 \text { MAAT } d+38.6961, \\
T_{e f f-M}= & 1.0270 T_{e f f-V}-0.4712,
\end{aligned}
$$

where $T_{e f f-V}$ is the effective temperature for base asphalt mixture at depth " $d,{ }^{\circ} \mathrm{C} ; T_{e f f-M}$ is the effective temperature for modified asphalt at depth " $d$," ${ }^{\circ} \mathrm{C}$; " $\mathrm{d}$ " is the pavement depth, cm; DD is average yearly air degree-days over $0^{\circ} \mathrm{C}$, $\times 1000^{\circ} \mathrm{C}$; MAAT is the mean annual air temperature, ${ }^{\circ} \mathrm{C}$.

The temperature-related data in Hebei are chosen, with DD of $13.3^{\circ} \mathrm{C}$ and MMAT of $13.6^{\circ} \mathrm{C}$. Then, the equivalent rutting temperature at different depths was calculated, and the calculation result is shown in Figure 4.

2.4. Determination of Frequency and Modulus Values at Different Depths. Odemark proposed a method for calculating frequencies by equivalent thickness. This method has been used in the mechanistic-empirical pavement design guide (MEPDG) in the United States [4]. In this paper, the MEPDG method was used to calculate the frequencies at different pavement depths.

In the MEPDG method of calculating frequency, the pavement's structural layer should be converted to an equivalent layer with the same modulus as the subgrade. Then, the loads can be assumed to spread at a diffusion angle of $45^{\circ}$. Once the calculated point is determined and the modulus at and above the point is assumed, the stress pulse length $L_{e f f}$ can be calculated. The calculation formula $L_{e f f}$ is shown in equation (5). The schematic diagram of this method is shown in Figure 5:

$$
\begin{aligned}
L_{e f f} & =2 \times\left(a_{c}+Z_{e f f}\right) \\
& =2 \times\left(a_{c}+\sum_{i=1}^{n-1}\left(h_{i} \sqrt[3]{\frac{E_{i}}{E_{S G}}}\right)+h_{n} \sqrt[3]{\frac{E_{n}}{E_{S G}}}\right),
\end{aligned}
$$

where $L_{e f f}$ is the length of the stress pulse at the calculation depth, $m ; a_{c}$ is the half-width of the applied load on top of the pavement surface, $m ; h_{i}$ is the thickness of pavement layer above the calculation point (excluding the layer where the calculation point is located), $m ; E_{i}$ is the moduli of pavement layer above calculation point (excluding the layer where the calculation point is located), $\mathrm{MPa} ; h_{n}$ is the thickness from calculation point to the top of the layer, $m ; E_{n}$ is the modulus of the layer to be calculated, MPa.

The frequency of the stress pulse is calculated as the inverse of the pulse time $[24,25]$. Therefore, as the duration of the stress pulse is determined, the corresponding frequency is calculated by

$$
f=\frac{1}{t}=\frac{v}{L_{e f f}},
$$

where $v$ is the truck speed, $\mathrm{m} / \mathrm{s}$, and $f$ is the frequency, $\mathrm{Hz}$.

Therefore, assuming the modulus and the truck speed, the frequency of the calculation point can be calculated. Utilizing the temperature, frequency, and the modulus 


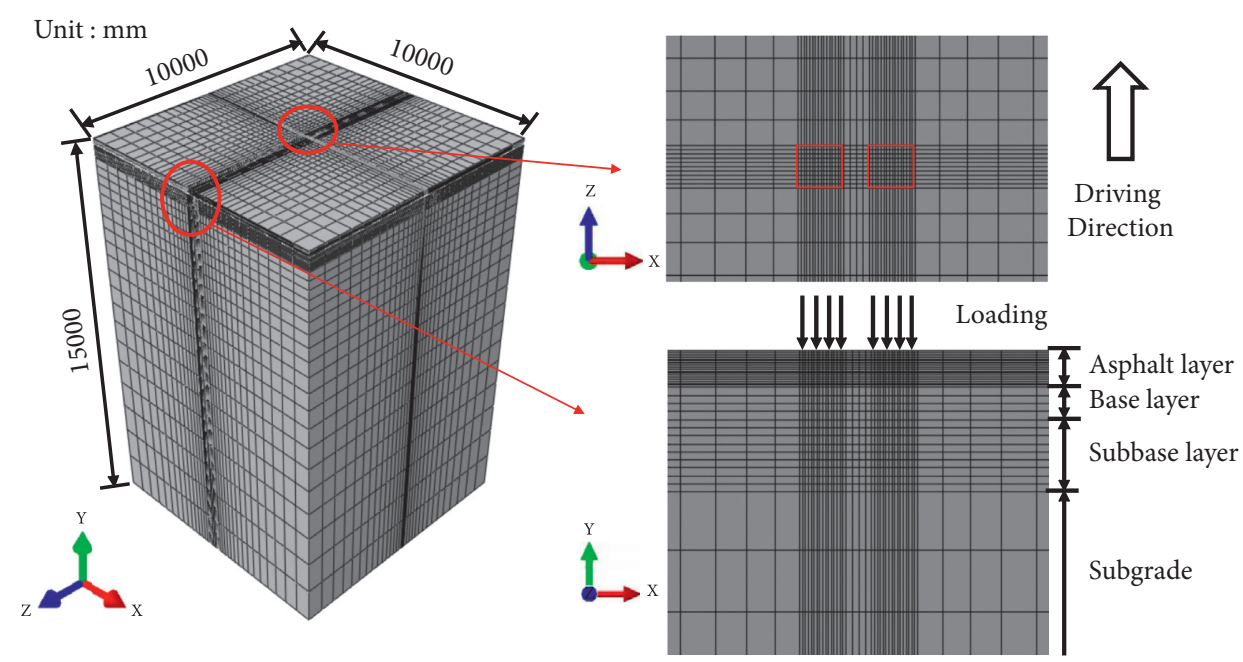

Figure 2: The finite element model.

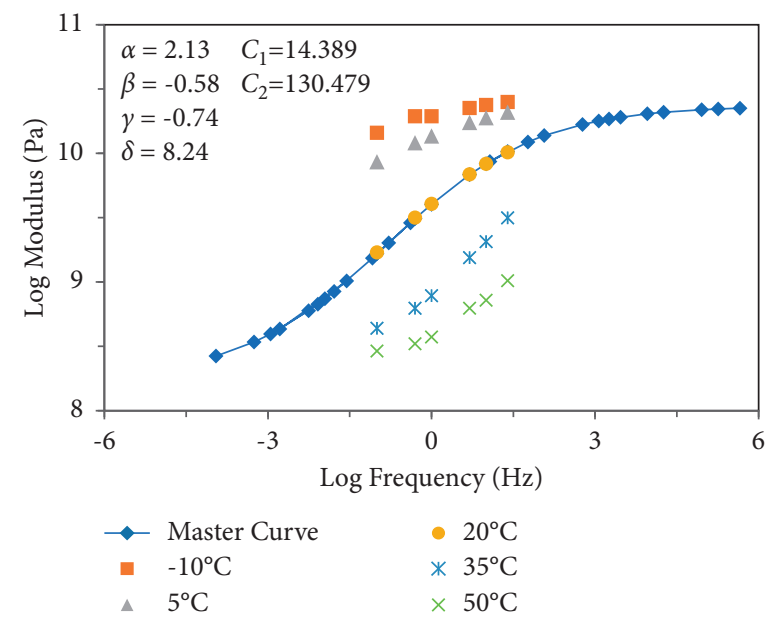

(a)

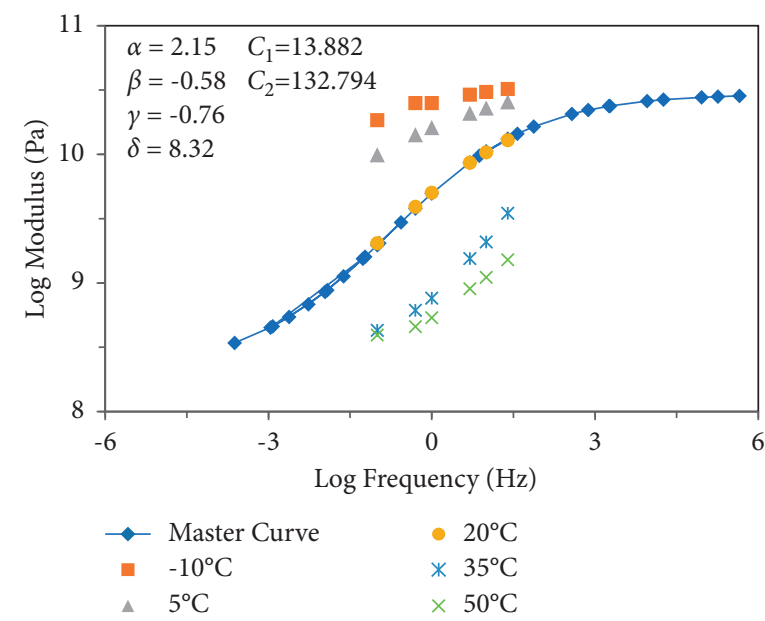

(b)

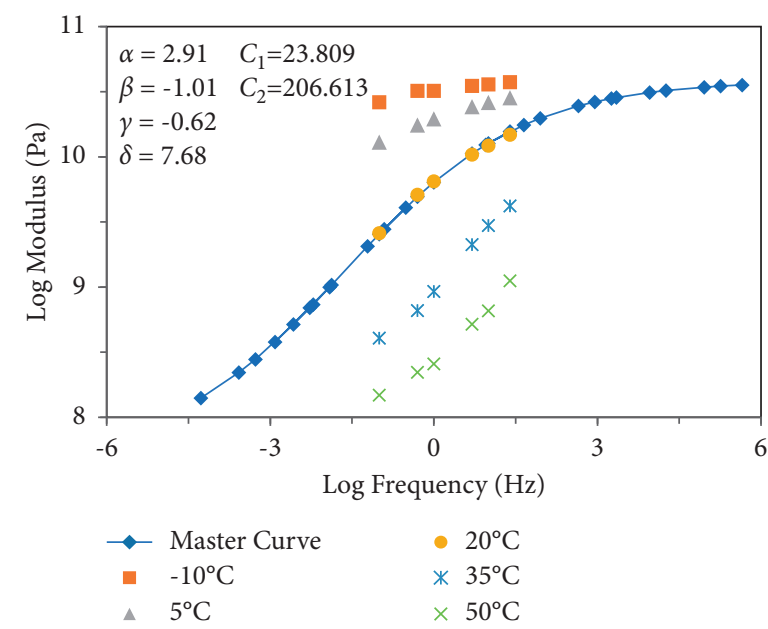

(c)

FIGURe 3: Dynamic modulus master curve and its fitting parameters: (a) AC-13, (b) AC-20, and (c) AC-25. 


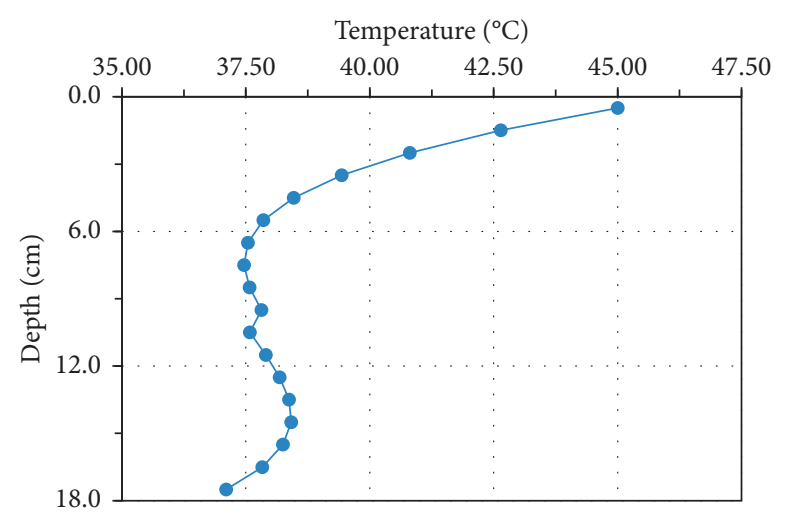

FIgURE 4: Equivalent rutting temperature.

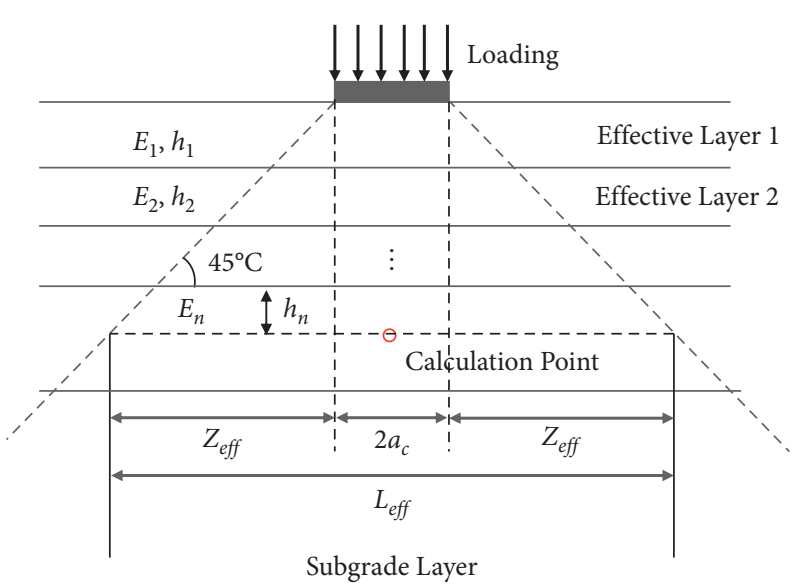

Figure 5: Schematic diagram of the length of the stress pulse.

master curve, another modulus of the calculation point can be determined. The modulus is determined by iteration until the difference between the assumed modulus and the calculated modulus is less than $0.1 \mathrm{MPa}$. Then, the modulus obtained is considered to be the final modulus of the calculation point. Assuming that the truck speed is $60 \mathrm{~km} / \mathrm{h}$, the calculated frequency and modulus at different pavement depths are shown in Figure 6.

From Figure 6, it can be seen that the frequency gradually decreases along with the depth. The modulus using the MEPDG method does not vary regularly along with the depth, which may be caused by the difference in dynamic modulus of each asphalt layer.

It has been known that the truck speed is an essential input parameter in calculating frequency and modulus from the above description. Therefore, the truck speed on the steep longitudinal slope section will be measured below.
2.5. Determine the Truck Speed on Steep Longitudinal Slope Sections. Heavy trucks are a fundamental cause of rutting in asphalt layers of asphalt pavements, while the effect of cars is negligible. In this study, nine steep longitudinal slope sections were selected to measure the truck speed at different points. At least 100 samples were measured at each point. A radar speed meter was utilized to measure truck speed. The results are shown in Table 2.

As shown in Table 2, the average truck speed decreases with the increase of gradient or slope length. The gradient has a more prominent effect on speed than the slope length. At the start of the slope (SS), the truck speed, gradient, slope length, and average truck speed at different points were used to fit regression analysis. The results and fitting equation are shown in Figure 7 and equation (7), respectively.where $y$ is the truck speed at the calculation point, $\mathrm{km} / \mathrm{h}, x_{\text {length }}$ is the length from the calculation point to the start of the slope, $x_{\text {gradient }}$ is the gradient of the steep longitudinal slope section, and $x_{\text {initialspeed }}$ is SS, $\mathrm{km} / \mathrm{h}$.

$$
y=-0.0141 \cdot x_{\text {length }}-5.4448 \cdot x_{\text {gradient }}+0.6863 \cdot x_{\text {initialspeed }}+41.48(R=0.9210) \text {, }
$$




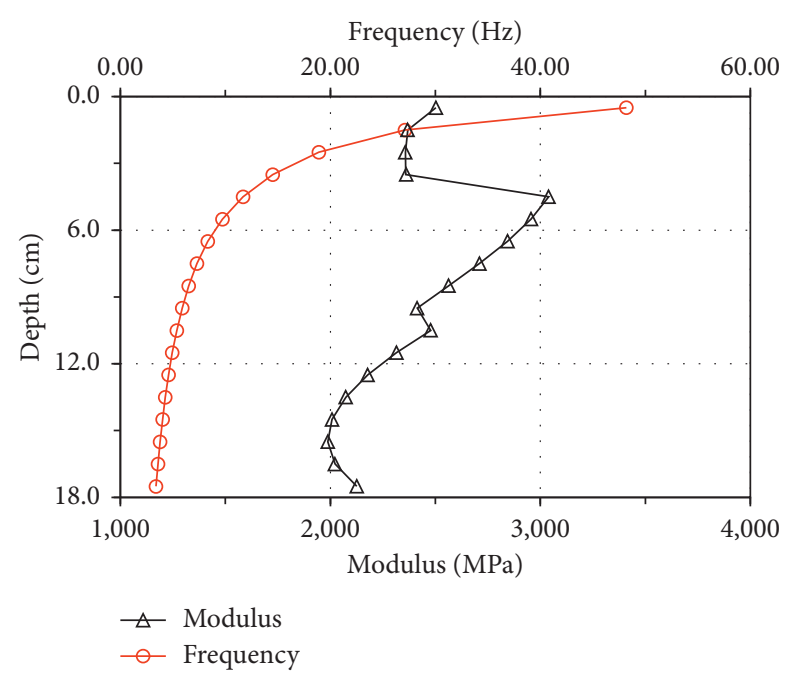

Figure 6: Modulus and frequency along with depth $(60 \mathrm{~km} / \mathrm{h})$.

TABLE 2: The average truck speed under different gradients and slope lengths.

\begin{tabular}{|c|c|c|c|c|c|}
\hline $\begin{array}{l}\text { Section } \\
\text { number }\end{array}$ & $\begin{array}{l}\text { Measured } \\
\text { point }\end{array}$ & $\begin{array}{l}\text { Gradient } \\
(\%)\end{array}$ & $\begin{array}{l}\text { Slope length } \\
(\mathrm{m})\end{array}$ & $\begin{array}{l}\text { Speed at the start of the slope (SS) } \\
\qquad(\mathrm{km} / \mathrm{h})\end{array}$ & $\begin{array}{l}\text { Speed at the end of the slope } \\
\qquad(\mathrm{km} / \mathrm{h})\end{array}$ \\
\hline \multirow{3}{*}{ No. 1} & 1 & \multirow{3}{*}{4.4} & 600 & \multirow{3}{*}{60} & 48 \\
\hline & 2 & & 200 & & 59 \\
\hline & 3 & & 0 & & 60 \\
\hline \multirow{3}{*}{ No. 2} & 4 & \multirow{3}{*}{4.7} & 800 & \multirow{3}{*}{50} & 39 \\
\hline & 5 & & 400 & & 44 \\
\hline & 6 & & 0 & & 50 \\
\hline \multirow{6}{*}{ No. 3} & 7 & \multirow{3}{*}{4.9} & 700 & \multirow{3}{*}{51} & 40 \\
\hline & 8 & & 500 & & 41 \\
\hline & 9 & & 0 & & 51 \\
\hline & 10 & \multirow{3}{*}{4.1} & 900 & \multirow{3}{*}{45} & 42 \\
\hline & 11 & & 400 & & 43 \\
\hline & 12 & & 0 & & 45 \\
\hline \multirow{7}{*}{ No. 4} & 13 & \multirow{4}{*}{5.28} & 700 & \multirow{4}{*}{42} & 32 \\
\hline & 14 & & 400 & & 28 \\
\hline & 15 & & 200 & & 40 \\
\hline & 16 & & 0 & & 53 \\
\hline & 17 & \multirow{3}{*}{4.92} & 800 & \multirow{3}{*}{34} & 32 \\
\hline & 18 & & 200 & & 33 \\
\hline & 19 & & 0 & & 34 \\
\hline \multirow{6}{*}{ No. 5} & 20 & \multirow{3}{*}{5.28} & 600 & \multirow{3}{*}{55} & 30 \\
\hline & 21 & & 400 & & 42 \\
\hline & 22 & & 0 & & 55 \\
\hline & 23 & \multirow{3}{*}{5.6} & 600 & \multirow{3}{*}{40} & 29 \\
\hline & 24 & & 300 & & 37 \\
\hline & 25 & & 0 & & 40 \\
\hline \multirow{3}{*}{ No. 6} & 26 & \multirow{3}{*}{4.73} & 1300 & \multirow{3}{*}{60} & 39 \\
\hline & 27 & & 600 & & 51 \\
\hline & 28 & & 0 & & 60 \\
\hline
\end{tabular}

As shown in Figure 7, equation (7) can characterize the relationship between the truck speed at the calculation point and gradient, slope length, and SS. Since the position at the end of the steep longitudinal slope generally causes the most severe rutting, the truck speed at the end of the slope was used to evaluate the rutting performance under different service conditions.
2.6. FEM Calculation Results and Model Validation. Based on the FEM calculation results, the maximum shear stress values at different points are extracted. The maximum shear stress value is calculated by

$$
\tau_{\max }=\frac{\sigma_{1}-\sigma_{3}}{2}
$$




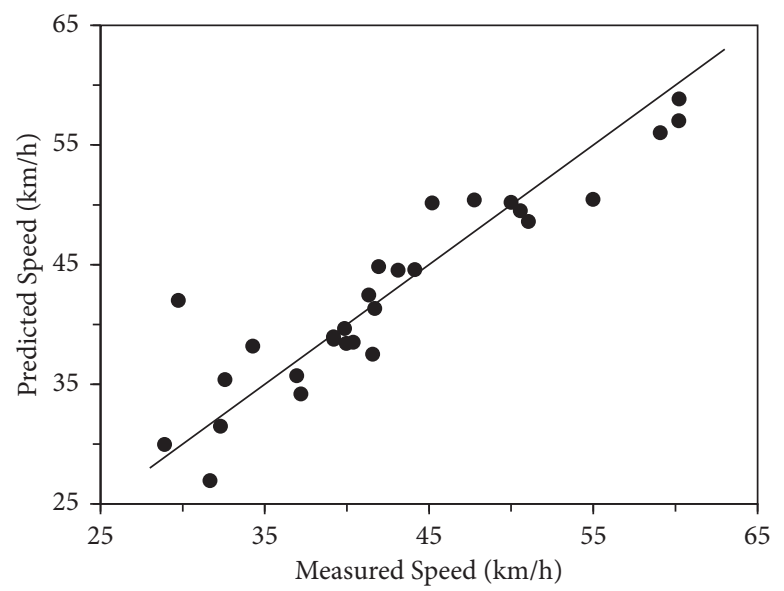

FIGURE 7: Comparison of the measured and predicted truck speed.

where $\tau_{\max }$ is the maximum shear stress value, $\mathrm{MPa} ; \sigma_{1}$ is the first principal stress, $\mathrm{MPa}$; and $\sigma_{3}$ is the third principal stress. The shear stress in the latter refers to the maximum shear stress.

The FEM calculated results are also compared with Bisar 3.0. The results obtained from two calculation software showed great agreement, proving that the established FEM is correct and can be used for further analysis.

\section{Improvement of the Shear Stress Calculation Method}

The truck speed was assumed as $60 \mathrm{~km} / \mathrm{h}$, which is the minimum driving speed specified on the highways in China. The value of the modulus at this speed is shown in Figure 6.

Rutting occurs due to shear deformation within the entire pavement [11], so the maximum value of shear stress at a certain depth is difficult to characterize the rutting behavior at that depth. The schematic diagram of mesh division is shown in Figure 8. The calculation points are numbered from left to right as "P1," "P2," "P3," "P4 “, "P5," "P6," "P7," "P8," "P9." The distribution of shear stresses along with depth for different points is shown in Figure 9.

It can be seen from Figure 9 that the maximum value of shear stress gradually transitions from the sides of the to the middle along the depth direction. Wang et al. [26] thought that the average value of the "P5," "P7," and "P9" could represent the shear stress at a certain depth of the pavement. However, the reason for using this method is not explicitly stated. Therefore, the "systematic clustering" method was used to cluster the distribution of these 9 points along the depth direction. One point distribution along with the depth represents a case.

The principle of systematic clustering is to combine the two closest cases of data points by calculating the distance between them and iterating this process iteratively until all data points are combined into one class. The clustering results are shown in Figure 10.

As shown in Figure 10, the calculated locations can be classified into two or three classes. Here, the results of the "systematic clustering" method were verified using K-means clustering. The results of K-means were consistent with those of systematic clustering, which proved the reliability of the "systematic clustering" method. From the perspective of accuracy, the nine positions can be classified into three classes. Therefore, the representative value of shear stress at a certain depth can be calculated by

$$
\bar{\tau}=\frac{5}{9} \tau_{5}+\frac{2}{9} \tau_{8}+\frac{2}{9} \tau_{9}
$$

where $\bar{\tau}$ is the representative shear stress at a certain depth, $\mathrm{MPa}$; and $\tau_{5}, \tau_{8}$, and $\tau_{9}$ represent "P5," "P8," and "P9" when the mesh is divided into $8, \mathrm{MPa}$.

For steep longitudinal slope sections, the low speed, the large horizontal force, and poor interlayer condition are the main characteristics. Therefore, this paper used the method mentioned to verify the clustering results. Here, consider the different speed conditions $(5 \mathrm{~km} / \mathrm{h}, 20 \mathrm{~km} / \mathrm{h}, 40 \mathrm{~km} / \mathrm{h}$, and $80 \mathrm{~km} / \mathrm{h}$ ), horizontal force coefficient of 0.5 , and poor interlayer bonding between layer and base layer (bonding coefficient is taken as 0.5 ). The results demonstrate the applicability of the method mentioned earlier.

\section{Results and Discussion}

4.1. Influence of Different Factors on the Shear Stress. Gradient and slope length are two critical parameters on the steep longitudinal slope section. In this section, poor interlayer bonding condition between asphalt and base layer is more likely to occur. Besides, trucks will apply a large horizontal force to the pavement structure due to frequent braking. So, the gradient, slope length, horizontal force, and interlayer bonding condition are analyzed here.

4.1.1. Gradient and Slope Length. The influences of gradient and slope length on shear stress are investigated first. Considering different gradients, the truck speed at the start of the slope (SS) is $60 \mathrm{~km} / \mathrm{h}$, and the slope length is $1000 \mathrm{~m}$. To analyze the effect of slope length, the SS is $60 \mathrm{~km} / \mathrm{h}$, and the gradient is $4 \%$. The distribution of the calculated shear stress along with the depth is shown in Figure 11. 


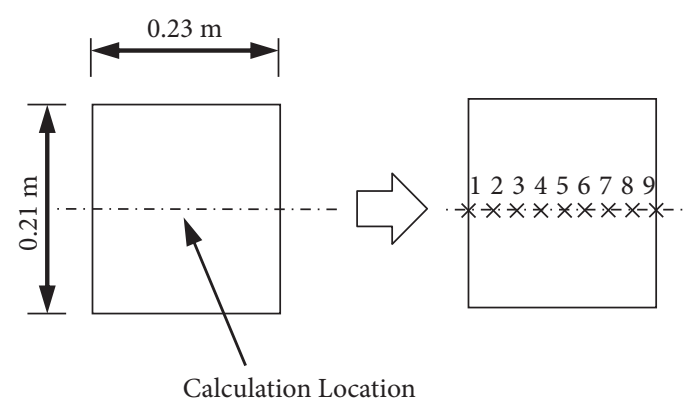

Figure 8: Schematic diagram of mesh division.

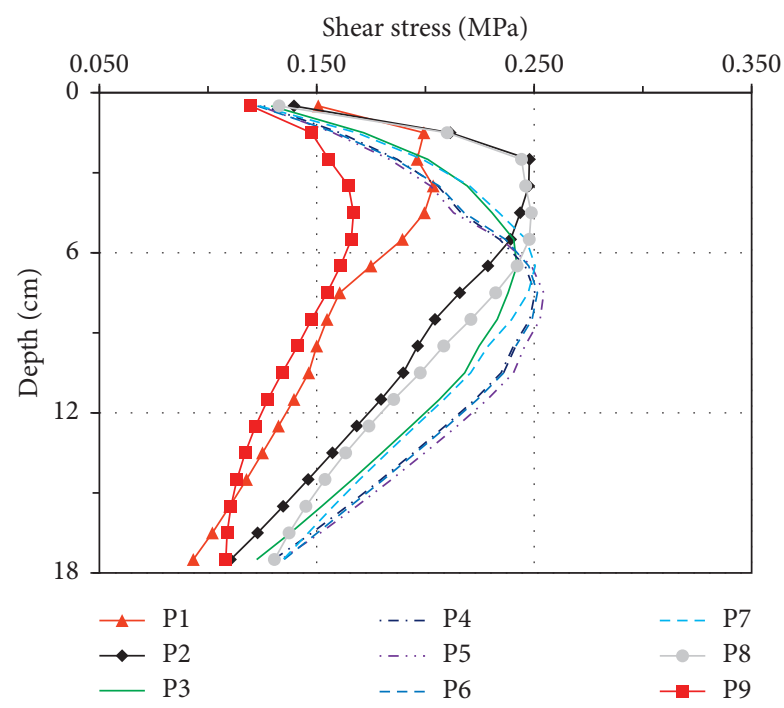

Figure 9: Distribution of shear stress at different depths.

As shown in Figure 11, gradient and slope length have almost no influence on the shear stress, and the distribution of shear stress along the depth shows a tendency to increase first and then decrease. This tendency is consistent with the fact that rutting is most severe in the middle asphalt layer. As the gradient and slope length ultimately affect the truck speed at the top of the slope, the influence of different truck speed on shear stress distribution is analyzed, as presented in Figure 12.

As demonstrated in Figure 12(a), the maximum value of shear stress is located at a depth of $6 \mathrm{~cm}$, and the value of shear stress tends to increase as the truck speed decreases. At a depth of $6 \mathrm{~cm}$, the shear stress at the speed of $5 \mathrm{~km} / \mathrm{h}$ is about $9 \%$ higher than that at the speed of $100 \mathrm{~km} / \mathrm{h}$. However, it can be seen that the shear stress is not very sensitive to truck speed. The truck speed can significantly impact the rutting performance, so the truck speed variable must be considered separately in the rutting prediction model.

4.1.2. Horizontal Force. The horizontal force coefficient is used in FEM. The horizontal force coefficient represents the ratio of horizontal force to vertical load. The truck speed is taken as $60 \mathrm{~km} / \mathrm{h}$, and the results are shown in Figure 13. "Normal" represents the case of no horizontal force.
As shown in Figure 13, the horizontal force has a noticeable influence on the shear stress at a depth of $0-5 \mathrm{~cm}$. The shear stress increases as the horizontal force coefficient becomes larger, showing a rising exponential trend, while the increase rate gradually decreases along with depth. Below $6 \mathrm{~cm}$, it can be seen that the horizontal force has a modest effect on the shear stress. As demonstrated above, the upper layer of the pavement is more sensitive to the change of horizontal force, so the upper layer in the steep longitudinal slope sections should be designed carefully.

4.1.3. Interlayer Bonding Condition. The shear stress is calculated with the interlayer bonding coefficients of $0.0,0.5$, and 1.0, respectively. The truck speed was taken as $60 \mathrm{~km} / \mathrm{h}$, and "normal" represents the case that the interlayer between the asphalt layer and base layer is completely bonding. The results are shown in Figure 14.

As presented in Figure 14, the shear stress inside the pavement gradually increases along with the depth compared to "normal." At $17 \mathrm{~cm}$ depth, the maximum value of shear stress is twice that of the case "normal." However, different interlayer bonding coefficients do not affect the distribution of shear stress with the same gradient and slope length. Therefore, sufficient attention should be paid to the 


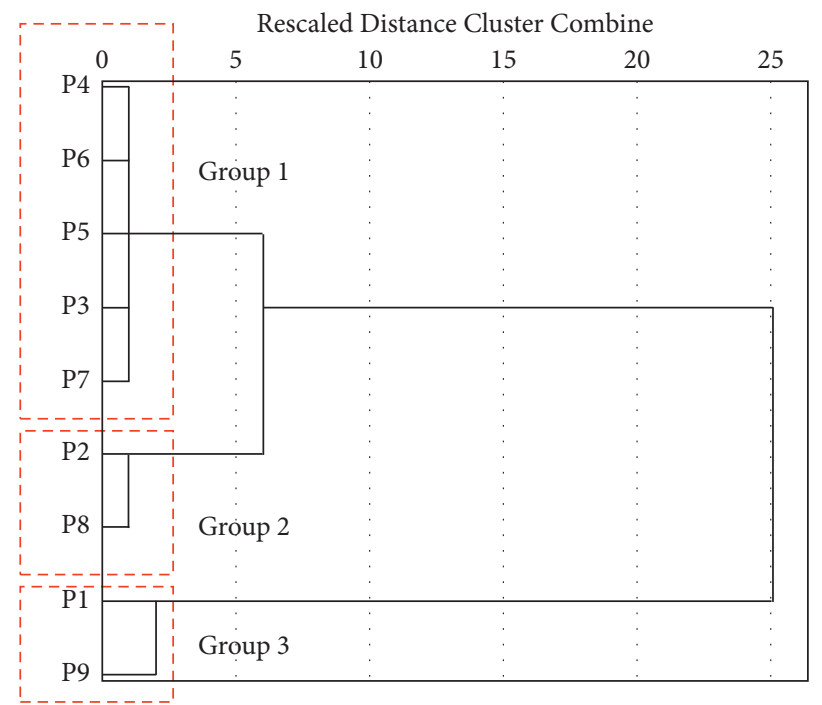

Figure 10: Clustering results.

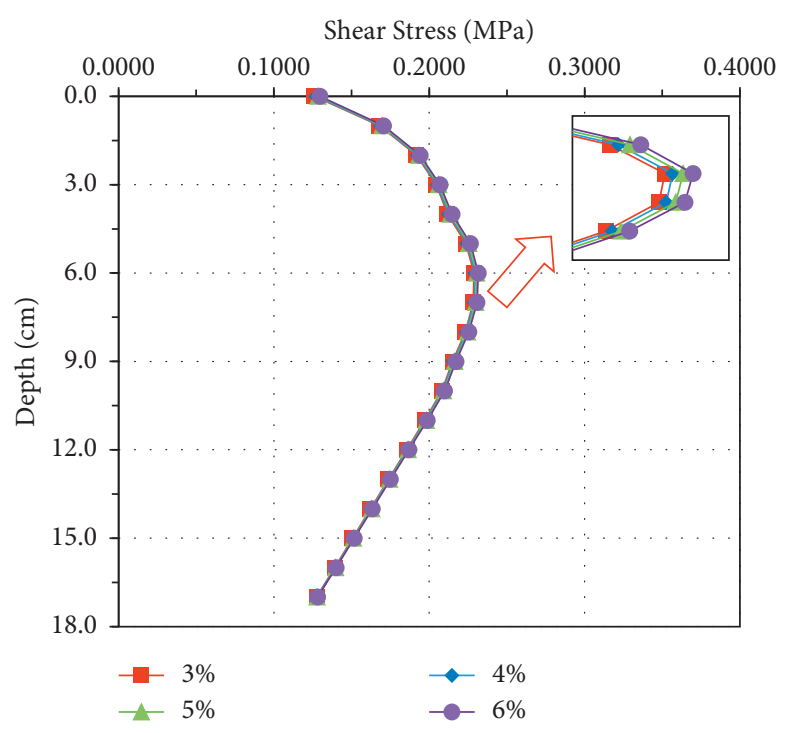

(a)

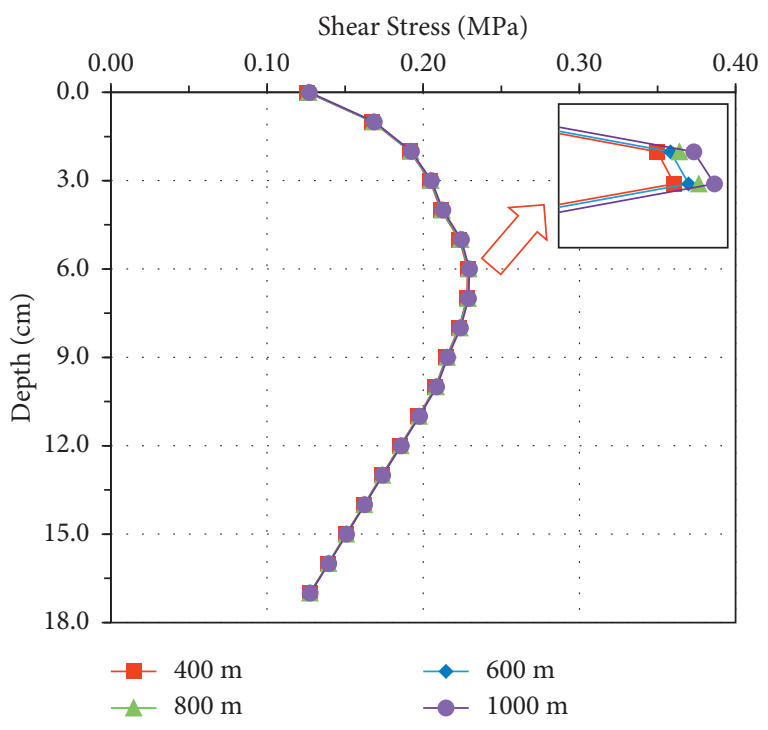

(b)

Figure 11: Distribution of shear stress values along with the depth: (a) different gradients and (b) different slope lengths.

interlayer bonding problem in pavement design and construction.

\subsection{Influence of Different Factors on the Rutting Performance.}

The rutting performance is generally evaluated using the index of rutting depth. Therefore, the rutting depth prediction model proposed by Sun [3] is used in this paper. The model takes the truck speed and the shear stress as essential input parameters. And this model can characterize the rutting depth well, considering the different factors mentioned above. The rutting prediction model is shown in

$$
R D=\left(1+L_{P}\right) \cdot \sum_{i=1}^{n} 10^{-7.6422} \cdot T_{i}^{3.7586} \cdot\left(\frac{N}{1+5.5572 V^{1.2219}}\right)^{0.8358 \cdot\left(\tau_{i} /[\tau]_{i}\right)^{0.6526}}
$$

where $R D$ is the rutting depth, $\mathrm{mm} ; L_{P}$ is the uphill coefficient, 0.505 for semirigid base asphalt pavement; $T_{i}$ is the equivalent rutting temperature of the asphalt sublayer $i,{ }^{\circ} \mathrm{C}$; $\mathrm{N}$ is the cumulative axle load, times; $V$ is the truck speed, 


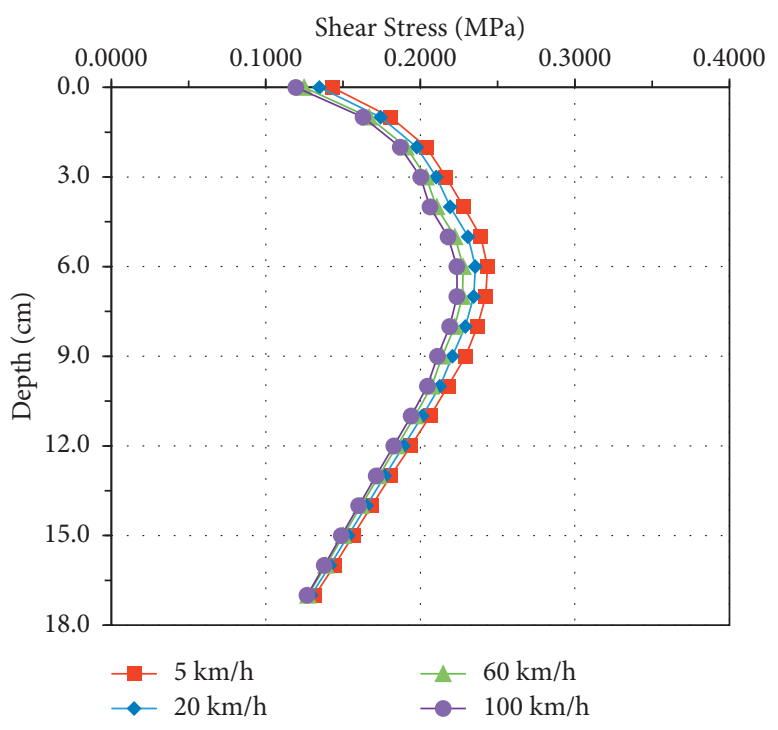

(a)

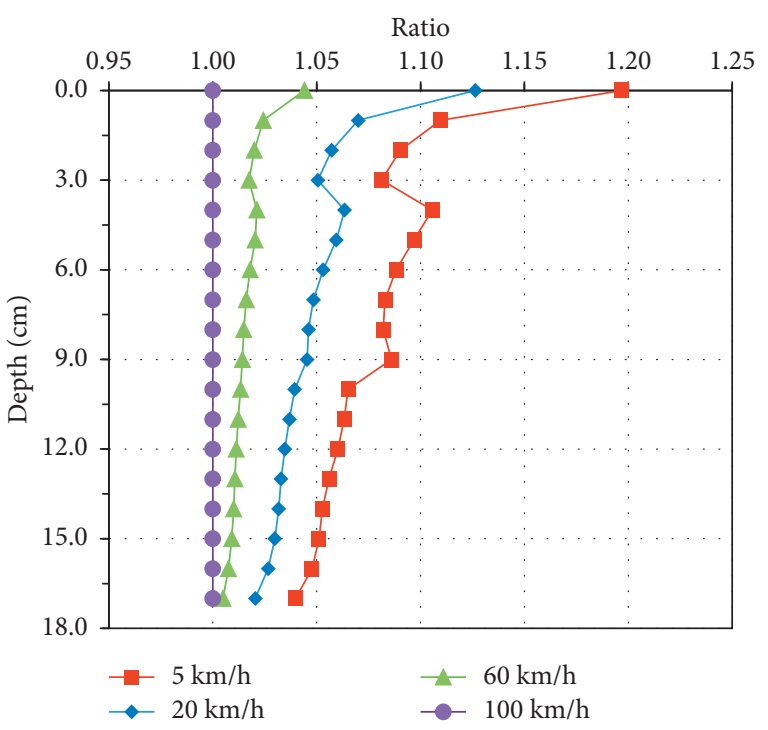

(b)

FIGURE 12: Distribution of shear stress along with the depth under the different truck speed: (a) normal value and (b) standardized value.

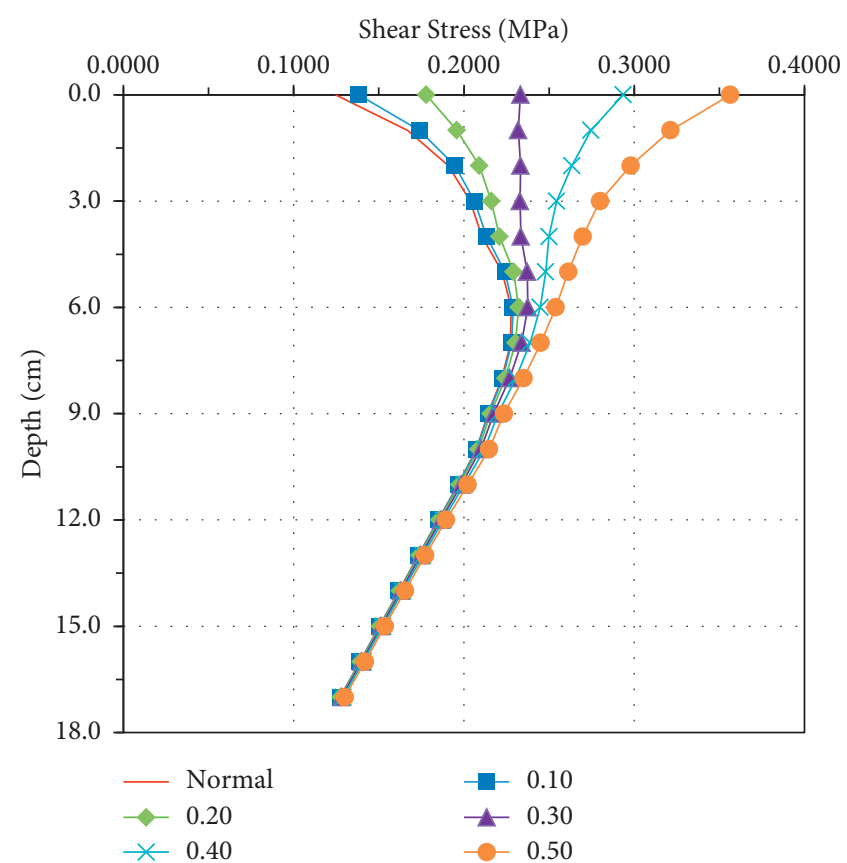

(a)

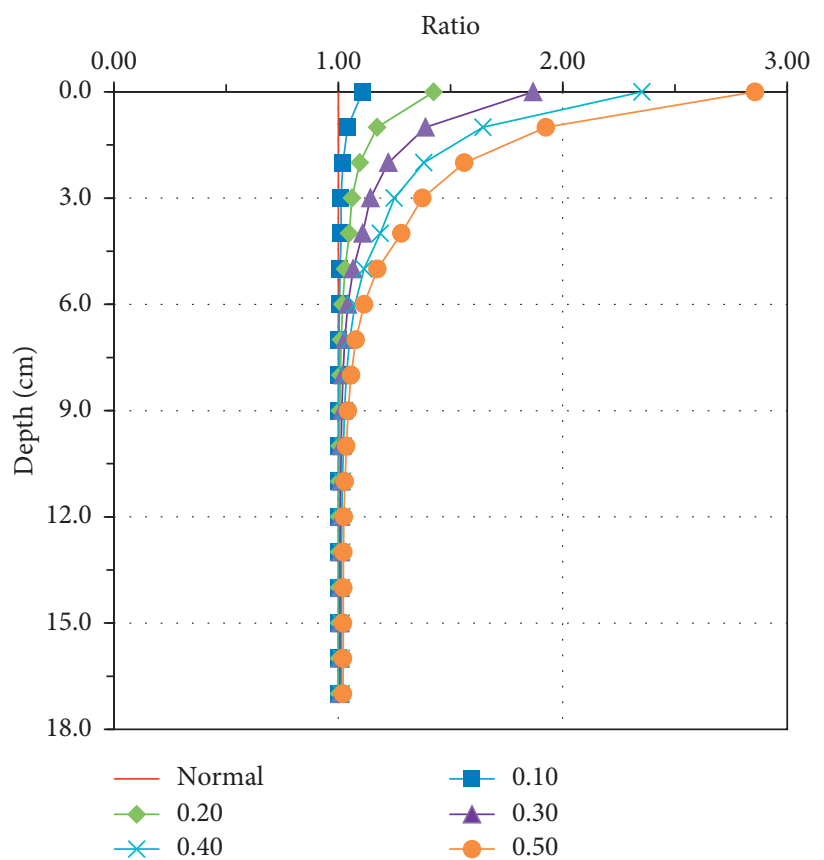

(b)

FIGURE 13: Effect of different horizontal forces on the distribution of shear stress along with the depth: (a) normal value and (b) standardized value.

$\mathrm{km} / \mathrm{h} ; \tau_{i}$ is the calculated shear stress of the asphalt sublayer, $\mathrm{MPa} ;[\tau]_{i}$ is the shear strength of the asphalt sublayer $i, \mathrm{MPa}$.

As shown in equation (9), this equation considers various factors that cause rutting and has a good differentiation for services conditions of steep longitudinal slope sections. Among them, the horizontal force and interlayer bonding condition can be characterized by the shear stress of each sublayer. The model considers the truck speed separately, which can reflect the influence of gradient and slope length.
4.2.1. Gradient, Slope Length, and the Truck Speed at the Start of the Slope (SS). This paper first analyzed the effects of different gradients, slope lengths, and SS on the rutting performance of steep longitudinal slope sections. The uphill coefficient is taken as 0.505 , the rutting equivalent temperature of each sublayer is taken as the temperature in Figure 4, and the cumulative axle load is taken as $1,000,000$ times. For the shear strength, $0.8 \mathrm{MPa}$ is taken for the AC-13 layer, and $0.6 \mathrm{MPa}$ is taken for both AC-20 and AC-25 layers. 


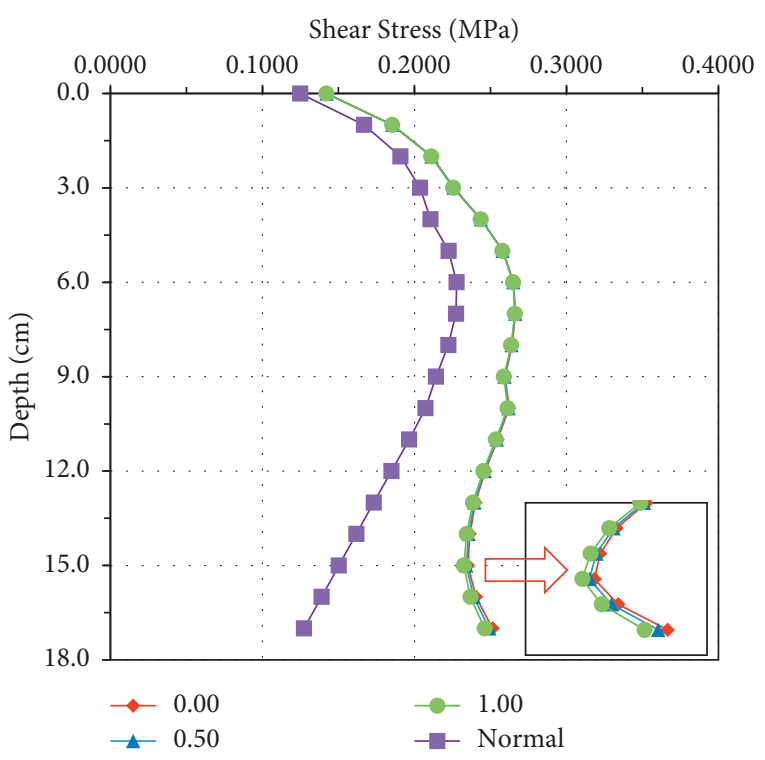

(a)

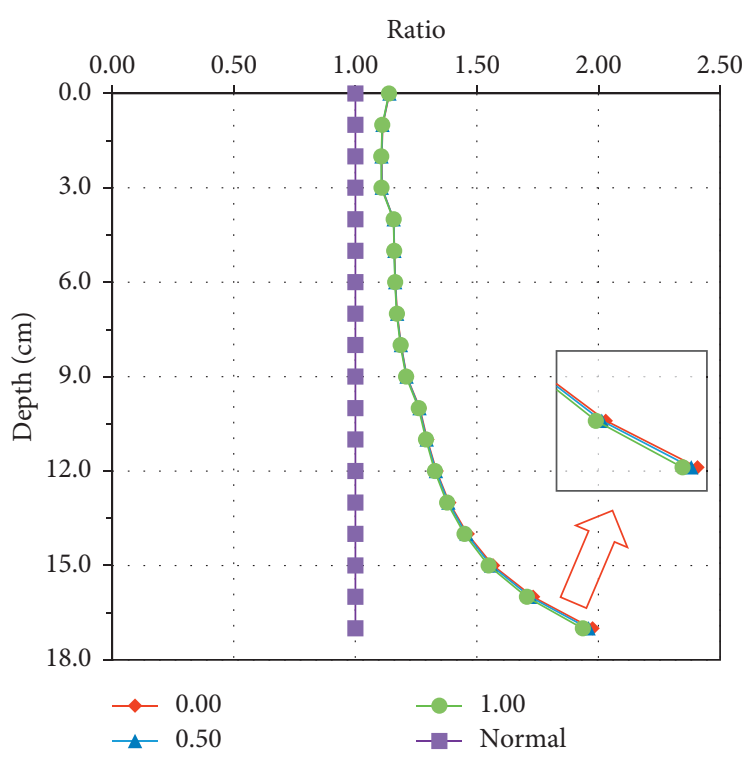

(b)

Figure 14: Effect of different interlayer bonding coefficients on the distribution of shear stress along with the depth: (a) normal value and (b) standardized value.

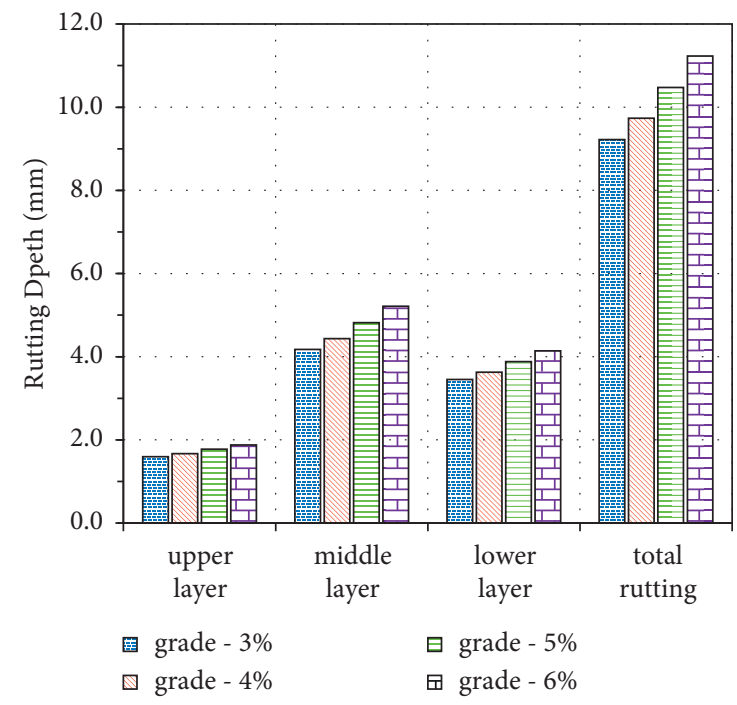

(a)

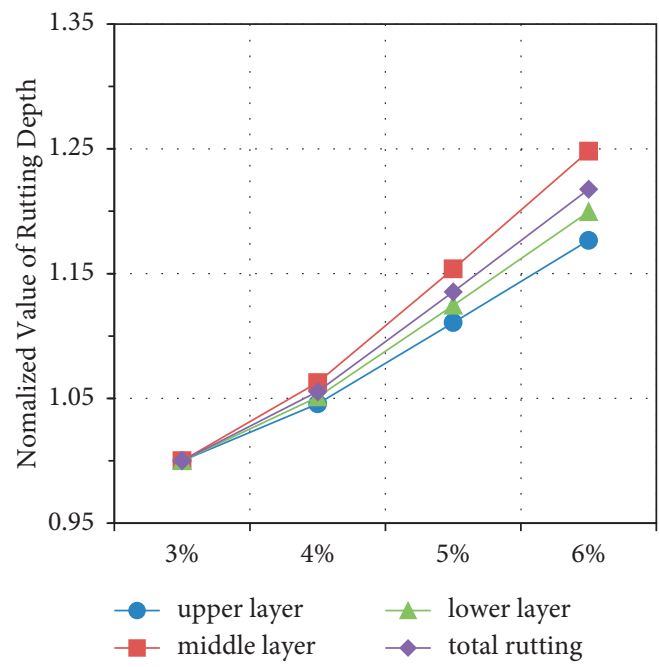

(b)

FIgURE 15: Rutting depth under different gradients: (a) normal value and (b) standardized value.

The top of the slope is chosen for further study as it is the most severe location for rutting. The truck speed is calculated by equation (7). Once the truck speed is obtained, the shear stress can be calculated by the method described above. When calculating the rutting depth under different gradients, the SS is $60 \mathrm{~km} / \mathrm{h}$, and the slope length is $1000 \mathrm{~m}$. The calculation results are shown in Figure 15. When considering different slope lengths, the SS is $60 \mathrm{~km} / \mathrm{h}$, and the gradient is $4 \%$. The calculation result is shown in Figure 16. The gradient is $4 \%$, and the slope length is $1000 \mathrm{~m}$ when considering the SS. The calculation result is shown in Figure 17.

Figures 15-17 show that the gradient, slope length, and SS significantly affect the rutting depth of asphalt pavement on steep longitudinal slope sections. With the increase of gradient and slope length, the increase of rutting depth shows an approximately linear relationship. Among them, the parameter of SS has the most significant effect on rutting depth. The total rutting depth increases by nearly 1.9 times for a speed of $20 \mathrm{~km} / \mathrm{h}$ compared to $60 \mathrm{~km} / \mathrm{h}$. Therefore, to reduce the rutting depth, the trucks should reach a relatively high speed before entering the steep longitudinal slope section. Once the truck speed is low when entering the slope, the rutting of this section will be severe.

It can also be seen that the rutting depth is most extraordinary in the middle layer. This result is consistent with the in-service pavements' results, thus proving the reliability 


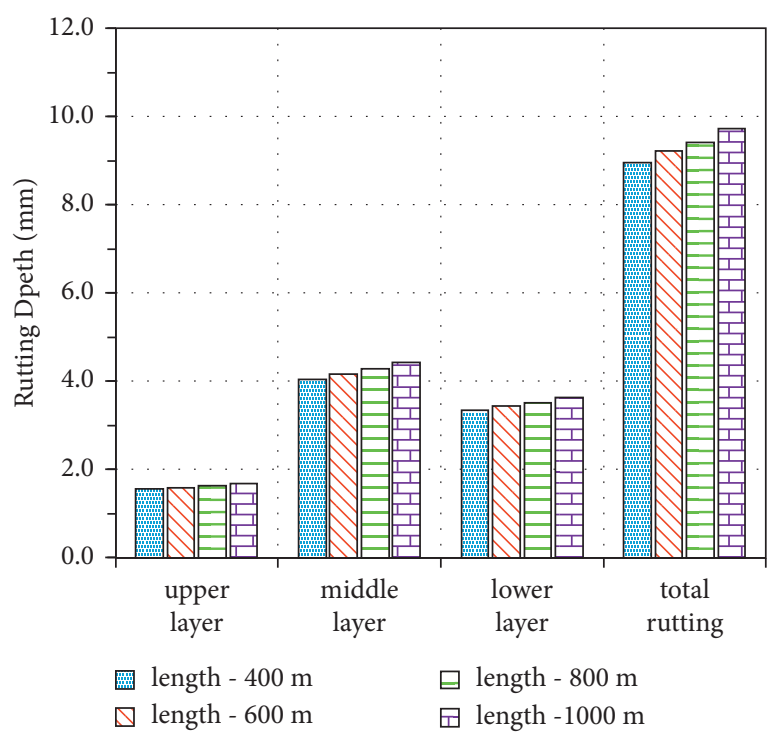

(a)

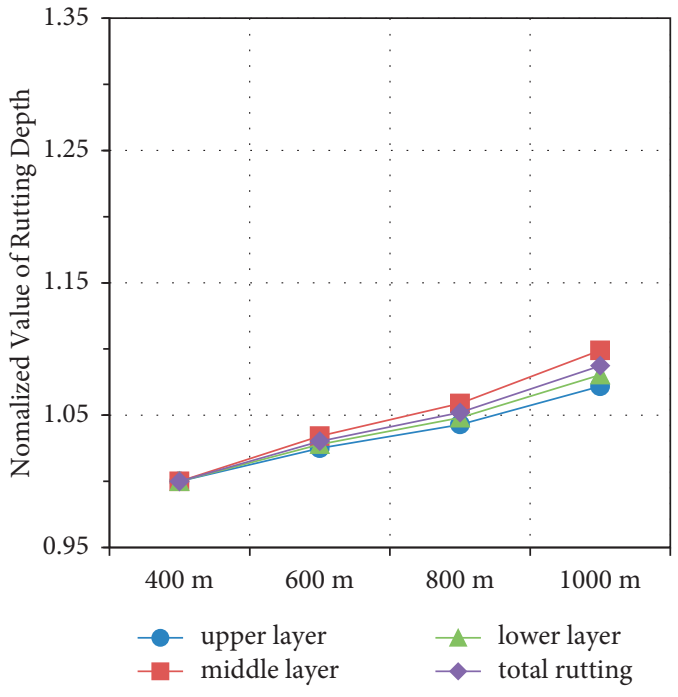

(b)

FIGURE 16: Rutting depth under different slope lengths: (a) normal value and (b) standardized value.

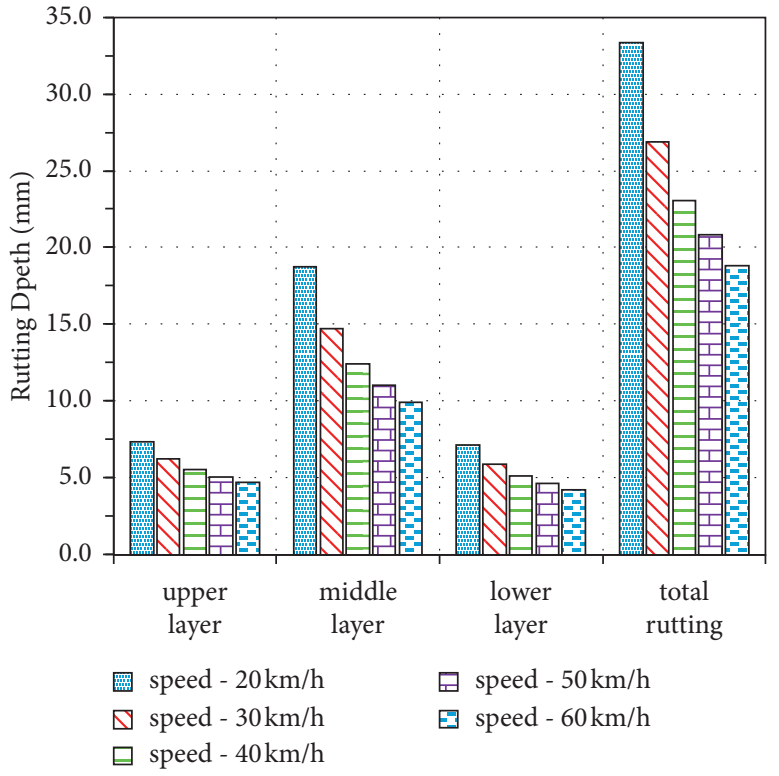

(a)

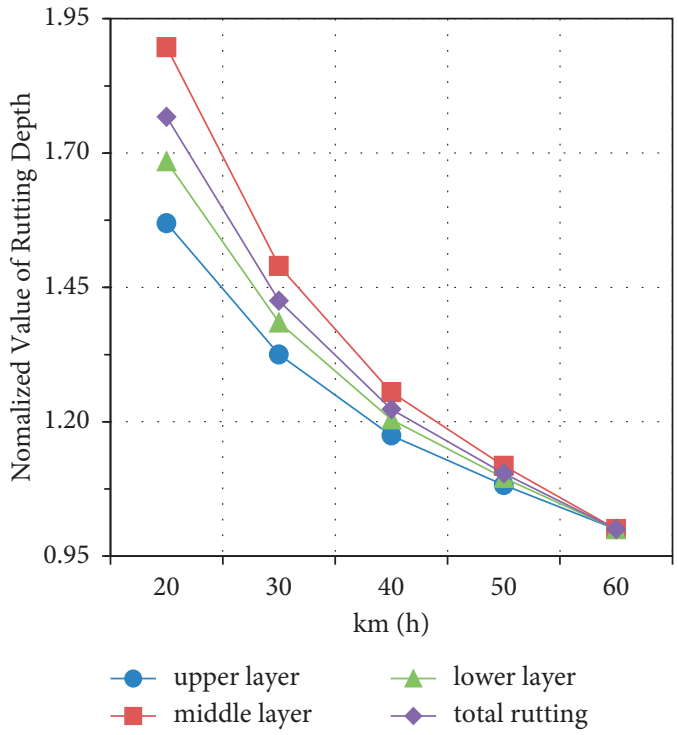

(b)

FIGURE 17: Rutting depth under different SS: (a) normal value and (b) standardized value.

and applicability of the rutting prediction model utilized in this paper.

\subsubsection{Horizontal Forces and Interlayer Bonding Conditions.} The assumptions of the model's parameters are the same as above, and the truck speed is maintained at a constant of $60 \mathrm{~km} / \mathrm{h}$. Four cases are considered here: Case 1, Case 2, Case 3, and Case 4.

Case 1 represents the normal condition. In this case, neither horizontal force nor interlayer bonding condition was considered. In Case 2, the horizontal force is considered, and the horizontal force coefficient is taken as 0.5 . Case 3 includes a poor interlayer bonding condition, and the interlayer bonding coefficient is taken as 0.5 . In Case 4 , both horizontal force and interlayer bonding coefficient are taken as 0.5. The calculation results are shown in Figure 18.

As shown in Figure 18, in Case 2, the rutting depth of the upper layer is 2.9 times compared with Case 1. When only the interlayer bonding condition existed, like in Case 3, the rutting depth of the lower layer is about 1.9 times that in Case 1 . The total rutting depth is the highest when considering poor interlayer bonding conditions and horizontal forces. However, compared to Case 2, the rutting depth of the upper layer was smaller in Case 4. This result is probably 


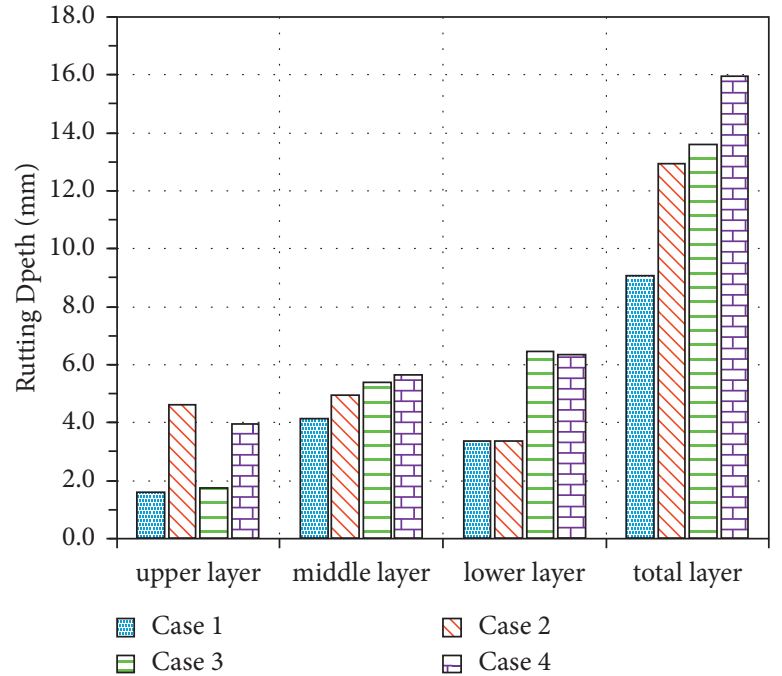

(a)

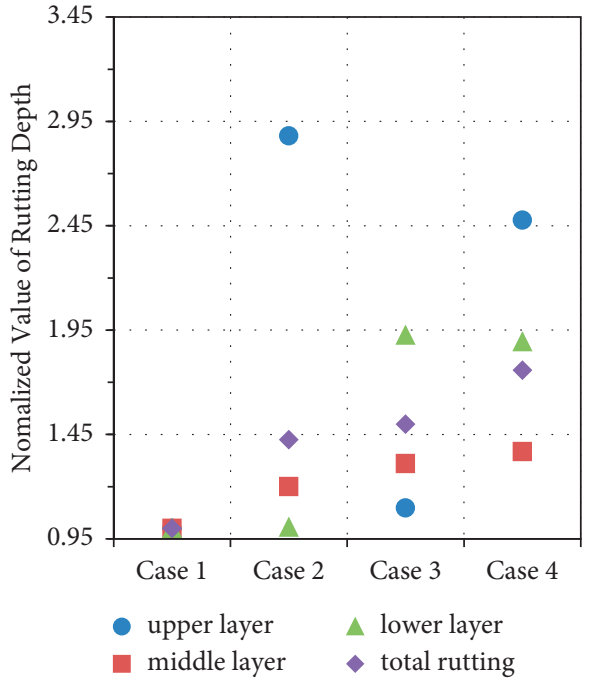

(b)

FIGURE 18: Effect of horizontal force and interlayer bonding on rutting depth: (a) normal value and (b) standardized value.

because the shear stress in the upper layer of the pavement is reduced to some extent due to the poor interlayer bonding.

\section{Conclusion}

In this paper, the truck speed at different positions of steep longitudinal slope sections was measured. Based on the measured speed, the parameters of steep longitudinal slope sections such as gradient and slope length can be quantitatively evaluated. Then, the shear stress distribution characteristics and rutting performance can be investigated. The main conclusions are as follows:

(1) It is feasible to use equations $y=a_{1} \cdot x_{\text {length }}+a_{2}$. $x_{\text {gradient }}+a_{3} \cdot x_{\text {initialspeed }}+a_{4}$ to describe the relationship among the truck speed at the start of the slope $\left(x_{\text {initialspeed }}\right)$, gradient $\left(x_{\text {gradient }}\right)$, slope length $\left(x_{\text {length }}\right)$, and the truck speed of calculation point. The truck speed of the steep longitudinal slope section can be predicted well based on the above equations.

(2) The shear stress calculation method is improved using the "systematic clustering" method, and the equation $\bar{\tau}=(5 / 9) \tau_{5}+(2 / 9) \tau_{8}+(2 / 9) \tau_{9}$ can represent the shear stress distribution of the whole pavement.

(3) The gradient and slope length do not influence the distribution of shear stresses. As the gradient and slope length affect the truck speed noticeably in the sections, the speed must be considered in the rutting prediction model as an influencing factor. The horizontal force and interlayer bonding condition can also affect the shear stress inside the pavement significantly.

(4) The middle layer contributes the most to the rutting depth under normal conditions. When there exists a considerable horizontal force, the contribution of the upper layer to the rutting depth is the largest. With an interlayer bonding problem, the rutting depth of the lower layer increases about twice that of the normal condition. Therefore, attention should be paid to the interlayer bonding problem in steep longitudinal slope sections.

\section{Data Availability}

All the data, models, and code generated or used during the study appear in the submitted article.

\section{Conflicts of Interest}

The authors declare no conflicts of interest.

\section{Acknowledgments}

The authors acknowledge the help provided by Prof. Lijun Sun, Prof. Liping Liu, Mr. Lingxiao Liu, and Mr. Tian Jin. This research was funded by the National Natural Science Foundation of China (5210081231), Postdoctoral Innovative Talents Program of China (BX2021216) and the Power China Road Bridge Group Co., Ltd. The sponsorships are gratefully acknowledged.

\section{References}

[1] C. Li and L. Li, "Criteria for controlling rutting of asphalt concrete materials in sloped pavement," Construction and Building Materials, vol. 35, pp. 330-339, 2012.

[2] L. Li, X. Huang, D. Han, M. Dong, and D. Zhu, "Investigation of rutting behavior of asphalt pavement in long and steep section of mountainous highway with overloading," Construction and Building Materials, vol. 93, pp. 635-643, 2015.

[3] L. J. Sun, Structural Behavior of Asphalt Pavements: Intergrated Analysis and Design of Conventional and Heavy Duty Asphalt Pavement, Butterworth-Heinemann, Oxford, UK, 2016. 
[4] Nchrp, Guide for Mechanistic-Empirical Design of New and Rehabilitated Pavement Structures, Final Report for Project 137A, Transportation Research Board, Washington, DC, USA, 2004.

[5] Ministry of Communications of China, Specifications for Design of Highway Asphalt Pavement; JTGD50-2017, China communication press, Beijing, China, 2017.

[6] Y. H. Nie and Q. Z. Zhang, "Analysis and application of shear stress in high-type asphalt pavement," Journal of Central South University, vol. 38, no. 6, pp. 1232-1238, 2007.

[7] E. J. Yoder and M. W. Witczak, Principles of Pavement Design, John Wiley \& Sons, Hoboken, NJ, USA, 1991.

[8] C. A. Drakos, R. Roque, and B. Birgisson, "Effects of measured tire contact stresses on near-surface rutting," Transportation Research Record: Journal of the Transportation Research Board, vol. 1764, no. 1, pp. 59-69, 2001.

[9] M. Novak, B. Birgisson, and R. Roque, "Tire contact stresses and their effects on instability rutting of asphalt mixture pavements: three-dimensional finite element analysis," Transportation Research Record: Journal of the Transportation Research Board, vol. 1853, no. 1, pp. 150-156, 2003.

[10] M. Novak, B. Birgisson, and R. Roque, "Near-surface stress states in flexible pavements using measured radial tire contact stresses and ADINA," Computers \& Structures, vol. 81, no. 811, pp. 859-870, 2003.

[11] E. Coleri, J. T. Harvey, K. Yang, and J. M. Boone, "Investigation of asphalt concrete rutting mechanisms by X-ray computed tomography imaging and micromechanical finite element modeling," Materials and Structures, vol. 46, no. 6, pp. 1027-1043, 2013.

[12] J. Zhu, L. Sun, Y. Wang, H. Li, and L. Liu, "Development and calibration of shear-based rutting model for asphalt concrete layers," International Journal of Pavement Engineering, vol. 18, no. 10, pp. 937-944, 2017.

[13] H. Wang and I. L. Al-Qadi, "Near-surface pavement failure under multiaxial stress state in thick asphalt pavement," Transportation Research Record: Journal of the Transportation Research Board, vol. 2154, no. 1, pp. 91-99, 2010.

[14] C. Xiao, C. F. Ai, and Y. J. Qiu, "Analysis on shear stress property of typical asphalt pavement under dynamic load," Journal of Highway and Transportation Research and Development, vol. 33, no. 7, pp. 19-26, 2016.

[15] I. L. Al-Qadi and P. J. Yoo, "Effect of surface tangential contact stresses on flexible pavement response," Journal of the Association of Asphalt Paving Technologists, vol. 76, no. 8, pp. 663-692, 2007.

[16] Y. Li, L. Liu, and L. Sun, "Temperature predictions for asphalt pavement with thick asphalt layer," Construction and Building Materials, vol. 160, pp. 802-809, 2018.

[17] N. Lushinga and J. Xin, "Effect of horizontal shear load on pavement performance," in Proceedings of the 2nd International Conference on Geological and Civil Engineering, vol. 80, Singapore, January 2015.

[18] H. Cheng, J. Liu, L. Sun, and L. Liu, "Critical position of fatigue damage within asphalt pavement considering temperature and strain distribution," International Journal of Pavement Engineering, pp. 1-12, 2020.

[19] H. Cheng, Y. Wang, L. Liu, and L. Sun, "Relationships between asphalt-layer moduli under vehicular loading and FWD loading," Journal of Materials in Civil Engineering, vol. 33, no. 1, Article ID 04020437, 2021.

[20] Y. Hu, G. Zang, L. Sun, L. Liu, and H. Cheng, "Determination of optimal identity points for backcalculating the structural layer moduli of asphalt pavement," Chinese Science Bulletin, vol. 65, no. 30, pp. 3287-3297, 2020.

[21] Ministry of Communications of China, Standard Test Methods of Bitumen and Bituminous Mixtures for Highway Engineering; JTG E20-2011, China communication press, Beijing, China, 2010.

[22] Y. Liao, Viscoelastic FE Modeling of Asphalt Pavements and its Application to US 30 Perpetual Pavement, Ohio University, Athens, OH, USA, 2007.

[23] Y. Li, L. Liu, F. Xiao, and L. Sun, "Effective temperature for predicting permanent deformation of asphalt pavement," Construction and Building Materials, vol. 156, pp. 871-879, 2017.

[24] H. Cheng, L. Liu, L. Sun, Y. Li, and Y. Hu, "Comparative analysis of strain-pulse-based loading frequencies for three types of asphalt pavements via field tests with moving truck axle loading," Construction and Building Materials, vol. 247, Article ID 118519, 2020.

[25] H. Cheng, L. Sun, Y. Wang, and X. Chen, "Effects of actual loading waveforms on the fatigue behaviours of asphalt mixtures," International Journal of Fatigue, vol. 151, Article ID 106386, 2021.

[26] Y. Wang, J. W. Zhu, and L. J. Sun, "Prediction model of shear deformation of asphalt mixture pavement," Journal of Tongji University, vol. 41, no. 11, pp. 1688-1696, 2013. 